\title{
GRADED ASSOCIATION BETWEEN CARDIORESPIRATORY FITNESS AND SKIN FOLDS THICKNESS IN ADOLESCENTS.
}

\author{
Journal website at; \\ http://mrtbjournal.org/index.php/njmr/issue/current/showToc
}

\author{
AO Akinpelu*, OO Oyewole ** and KS Oritogun*** \\ *Department of Physiotherapy, College of Medicine, University of Ibadan, Ibadan. \\ **Department of Physiotherapy, Olabisi Onabanjo University Teaching Hospital, Sagamu, Ogun State. \\ ***Department of Medical Microbiology and Parasitology (Biostatistics Unit), Olabisi Onabanjo University \\ Correspondence to: \\ OO Oyewole \\ oyewoleye@yahoo.co.uk \\ P.O. Box 343, Sagamu, Ogun state.
}

\section{SUMMARY \\ Background: Body fatness and cardiorespiratory fitness (CRF) are both related to health, and their interrelation to each other has been documented but with little information on Nigeria population.}

Objective: The purpose of this study was to evaluate relationship between cardiorespiratory fitness and skin folds, and if this relation is linear or curvilinear.

Methods: A cross-sectional survey of secondary school students in Sagamu local government area of Ogun state, Nigeria during 2006 school year was carried out. Representative samples of 1638 apparently healthy students were selected from 11 schools with age ranged between 12 and 18 years. Their CRF, triceps and abdominal skin folds were measured.

Results: The results showed a significant negative correlation between the variables but not significant for males' triceps and sum of skin folds. There were significant graded relation between cardiorespiratory fitness and skin folds; the relations were curvilinear in the whole population. Coefficients of determination $\left(\mathrm{R}^{2}\right)$ for cardiorespiratory fitness were $6.02 \%, 5.33 \%$ and $6.2 \%$ for triceps, abdominal and sum of skin folds respectively.

Conclusion: It is therefore, imperative to encourage participation in physical activities to improve fitness and thereby reduces the measure of adiposity.

Key word: Cardiorespiratory fitmess, skin folds, body sathess, adolescents

\section{INTRODUCTION}

Bcth abdominal fat and low cardiorespiratory fitness (CRF) are significant predictors of health risk, but the independent contribution of these two factors is not firmly established. It is well established that aerobic exercise is cardioprotective (Eckel, 1997; Thompson et al, 2003) and that being overweight increases the risk of cardiovascular disease (CVD) (Calle et al, 1999; Wilson et al, 2002). However, because low physical activity and increased adiposity often occur in combination, masking their independent effects, it is unclear whether lower aerobic fitness or higher body fatness exerts a greater influence on CVD risk factors (Christou et al, 2005). Regular physical activity has been reported to be an effective means of improving $\mathrm{CRF}$ and reducing waist circumference, visceral fat, and subcutaneous fat independent of a corresponding change in body mass index (BMI) (Ross et al, 2000; Ross et al, 2004).

Skin fold thickness was related to a high risk profile regarding coronary heart disease (CHD), hence can be used to predict CHD (Twisk et al, 1998). In general, skin fold measurement contribute only marginally to improved prediction of risk of ischaemic heart disease (IHD) as measured by BMI, but central obesity, as measured by the subscapular skin fold, is predictive of IHD independently of BMI (Yarnell et al, 2001). Triceps skin fold predicted total fat content well in male children and adolescents (Sarria et al, 2001). The reports from the Aerobics Center Longitudinal Study present convincing evidence that fitness is a more potent risk factor for mortality than is fatness and that fitness attenuates the effect of obesity on mortality (Stevens et al, 2002).

The relationship of cardiorespiratory fitness and indices of adiposity has been reported in the literature. Previous study has shown that individuals with moderate CRF had lower levels of total fat mass and abdominal subcutaneous and visceral fat than individuals with low CRF for a given BMII (Janssen et al, 2004). It has been observed that for both men and women the mean body 
weight, BMI, triceps skin fold thickness, sum of four skin fold measurements, predicted percentage of body fat and waist-hip ratio were significantly lower with increasing fitness (Jette et al, 1992). It was reported that sum of skin folds, subscapular and truncal skin fold thickness, BMI and percent body fat were lower in overweight and obese youths with high CRF in comparison with youths at the same BMI category with low CRF (Nassis et al, 2005). However, studies analyzing the graded relation between cardiorespiratory fitness and skin folds in this population are scarce. Therefore, the purpose of this study was to evaluate relationship between cardiorespiratory fitness and skin folds, and if this relation is linear or curvilinear.

\section{MATERIALSAND METHODS}

During 2006 school year, a cross-sectional survey of secondary school students in Sagamu local government area of Ogun state, Nigeria was carried out. Thirty one secondary schools were in the area, 16 public and 15 private schools. The sample of 11 schools (8public and 3 private) was drawn by stratifying the school into public and private schools. Participants were drawn from the selected schools by probability proportional to size from various arms of the classes. Total of 1638 (790 male and 848 female) apparently healthy students were selected.

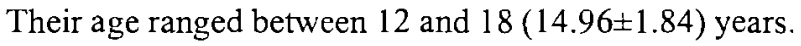
The protocol for this research was approved by Institutional Review Committee of University of Ibadan and University College Hospital, Ibadan. Informed consent was sought from the participants and their parents; permission was sought from local education authority and the principals of the selected schools. The nature, purpose and procedure of the study were explained to the participants in detail. The biodata of each participant was taken: this included age (as at last birth day) and sex. Each of the participants was medically screened for any disability and pathology.

\section{Measurements}

Cardiorespiratory fitness: Cardiorespiratory fitness index was calculated using 3-minute step test. The participant was dressed in suitable clothes and the procedure was explained and demonstrated. The protocol is described in the previous study (Akinpelu et al, 2007). The Cardiorespiratory fitness index (CRFI) was computed with the following formula: $\mathrm{CRFI}=$

Duration of exercise in second X 100 (Amusa and Udoh, 1982)

$2 \mathrm{X}$ sum of pulse counts in recovery

Skin folds: The American College of Sports Medicine guidelines for skin fold measurement was followed to measure triceps and abdominal skin fold thickness using Skin fold caliper (FAT-O-METER, Novel products Inc., Pat. No.4.233.743). The triceps skin fold was taken at the level of mid-point between the acromion and olecranon processes and $5 \mathrm{~cm}$ adjacent to the umbilicus to the right side for abdominal skin fold thickness as described by ISAK (2001). Two readings were taken on each site and the average was used in the computation.

\section{Data Analysis}

Data analysis was done with computer software package (SPSS version 15.0). Descriptive statistics (mean $\pm \mathrm{SD}$ ) were used to examine the data as appropriate. Pearson correlation was used to find the strength of the relationship between cardiorespiratory fitness and skin folds. Regression analysis was carried out to see relationship between the variables. The graded relations between CRF and skin folds were carried out using Microsoft excel. Pvalue $<0.05$ was taken as significant.

\section{RESULTS}

Table 1 shows descriptive variables of the study population. Males were significantly older than the females. Boys were significantly fit than the girls while the girls were higher significantly in fatness than the boys. Table 2 presents correlation matrix between cardiorespiratory fitness and skin folds. There were significant negative correlation between the variables but not significant for males' triceps and sum of skin folds.

Figures 1-3 show the relation between cardiorespiratory fitness and triceps, abdominal and sum of skin folds respectively for the whole population. Triceps skin fold showed a significant curvilinear ( $3^{\text {rd }}$ degree polynomial) relation with cardiorespiratory fitness. The regression equation was [Triceps skin fold $\left(\mathrm{y}_{1}\right)=4 \mathrm{E}-06 \mathrm{x}^{3}+0.0043 \mathrm{x}^{2}-$ $0.7258 x+37.893]$. Cardiorespiratory fitness explained $6.02 \%$ of total variance. Abdominal skin fold also showed a significant curvilinear ( $3^{\text {rd }}$ degree polynomial) relation with cardiorespiratory fitness. The regression equation was [Abdominal skin fold $\left(y_{2}\right)=3 E-05 x^{3}-0.0028 x^{2}-$ $0.1235 x+21.131]$. The percentage contribution to the total variance from cardiorespiratory fitness was $5.33 \%$. Sum of skin folds as well demonstrated a significant curvilinear ( $3^{\text {rd }}$ degree polynomial) relation with cardiorespiratory fitness. The regression equation was [Sum of skin folds $\left.\left(\mathrm{y}_{3}\right)=3 \mathrm{E}-05 \mathrm{x}^{3}+0.0015 \mathrm{x}^{2}-0.8492 \mathrm{x}+59.021\right]$. Cardiorespiratory fitness explained $6.2 \%$ of total variance.

Table 1: Descriptive Statistics by Gender

\begin{tabular}{llll}
\hline Variables & $\begin{array}{l}\text { Male } \\
(\mathbf{n = 7 9 0 )} \\
\text { Mean(SD) }\end{array}$ & $\begin{array}{l}\text { Female } \\
(\mathbf{n = 8 4 8 )} \\
\text { Mean(SD) }\end{array}$ & $\mathbf{p}$ \\
\hline Age(years) & $15.1(1.9)$ & $14.8(1.8)$ & .001 \\
CRF & $67.8(9.3)$ & $63.7(11.7)$ & .000 \\
TSF (mm) & $6.4(3.0)$ & $14.1(5.3)$ & .000 \\
ASF $(\mathrm{mm})$ & $6.9(2.6)$ & $12.7(4.3)$ & .000 \\
SSF(mm) & $13.3(5.1)$ & $26.9(8.9)$ & .000 \\
\hline
\end{tabular}

Key: $C R F=$ Cardiorespiratory Fitness, $T S F=$ Triceps skin fold $\mathrm{ASF}=\mathrm{Abdominal}$ skin fold, $\mathrm{SSF}=\mathrm{Sum}$ of skin fold 
Table 2: Correlation Matrix between Cardiorespiratory Fitness and Skin folds

$*$
$*$

$\mathrm{SSF}=$ sum of skin fold, $\mathrm{CRF}=$ Cardiorespiratory Fitness **Correlation is significant at the .01 level (2-tailed)

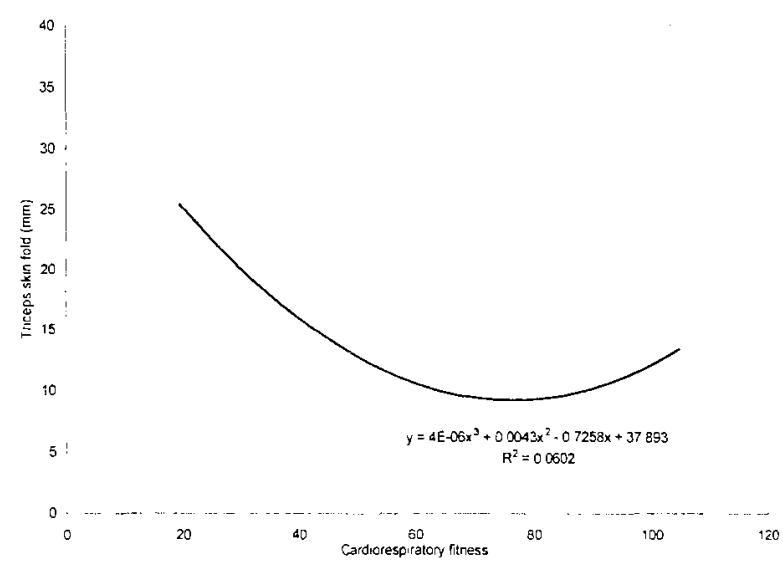

Fig 1: Graded relation between cardiorespiratory fitness and triceps skin fold

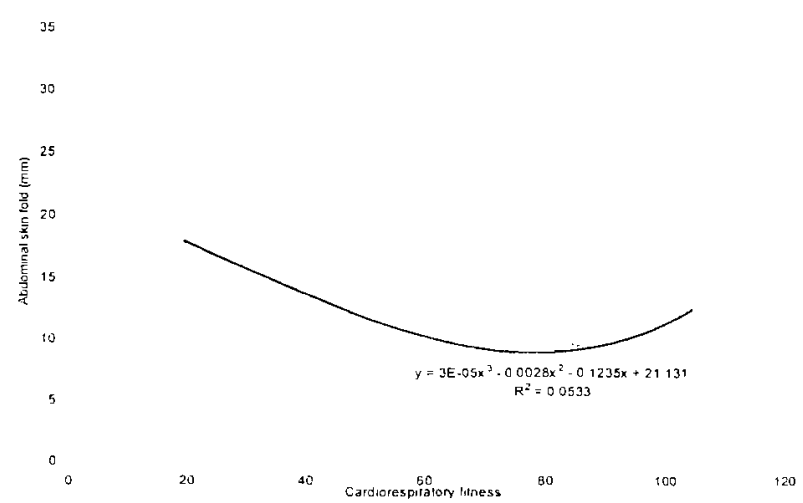

Fig 2: Graded relation between cardiorespiratory fitness and abdominal skin fold

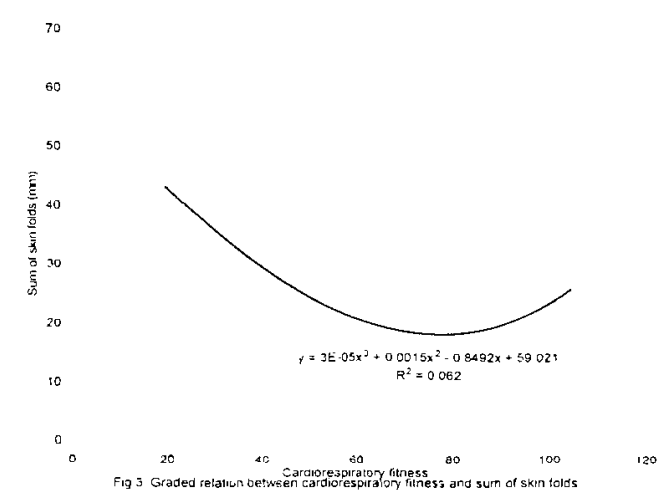

Fig 3: Graded relation between cardiorespiratory fitness and sum of skin folds

\section{DISCUSSION}

The present study evaluated the graded associations between cardiorespiratory fitness and skin folds in a representative sample of secondary school student's adolescents. A graded relation between cardiorespiratory fitness and skin folds (triceps, abdominal and sum of skin folds) was demonstrated. The relation was curvilinear in the whole population. The third degree term of the fitness variable, which could indicate a more complex association than a second order polynomial, was significant for triceps, abdominal and sum of skin folds and only explained $6.02 \%, 5.33 \%$ and $6.2 \%$ of the total variation in triceps, abdominal and sum of skin folds respectively.

The results in the present study show a significant negative correlation between anthropometric variables and cardiorespiratory fitness in the whole population, which has also been reported earlier in children and adolescents (Boreham et al, 2001; Ekelund et al, 2001). When the data was adjusted for sex, a gender differences was seen in the relationship between cardiorespiratory fitness and anthropometric variables. The male students do not show a significant correlation with exception of abdominal skin fold. This observation was in contrast to the study of Mota et al, (2006). In that study, it was shown that cardiorespiratory fitness expressed indirectly was inversely and significantly associated with fatness, in both sexes. None of the previous studies analysed whether the association between cardiorespiratory fitness and skin fold was curvilinear in Nigeria population which the present study explored. It was observed that the relationship was curvilinear in Nigeria adolescents. The same observation was reported in European children and adolescents (Klasson-Heggebo et al, 2006).

Literature showed that there is an interest in the relationship between cardiorespiratory fitness and other indicators of health status, including obesity. Low levels of activity and fitness are a major public health problem in many countries (Mota et al, 2002). Although the mechanism by which high cardiorespiratory fitness reduces the risk of obesity is not clear, relationships of aerobic fitness and fatness to some risk factors were found even in childhood (Maffeis et al, 2003). Therefore, a measure to increase childhood cardiorespiratory fitness should be taken in order to reduce the risk of obesity. Results from the Muscatine study have pointed out that children who improve their cardiorespiratory fitness during childhood have less overall adiposity and less abdominal adiposity than their counterparts during adolescence (Janz et al, 2002). Participation in vigorous physical activities has been shown to relate inversely to fat deposition in male adolescents (Dionne et al, 2000). It is therefore, imperative to encourage participation in physical activities to improve fitness and thereby reduces the measure of adiposity. 


\section{CONCLUSION}

In this sample of Nigerian adolescents, a curvilinear relation was found between cardiorespiratory fitness and skin folds. It is therefore, imperative to encourage participation in physical activities to improve fitness and thereby reduces the measure of adiposity. It is therefore important to direct action towards those adolescents who have low cardiorespiratory fitness.

\section{REFERENCES}

- Akinpelu AO, Oyewole OO, Oritogun KS (2007). Relationship between cardiorespiratory fitness and blood pressure of Nigerian adolescents. Nigerian Journal of Medical Rehabilitation 12(1\&2): 1 -5

- Amusa L.O and Udoh C.O. Dynamics of Physical Fitness 1982. Osogbo. Adebara Publishers, page 1-17.

- Boreham C, Twisk J, Murray L, Savage M, Strain JJ, Cran $\mathrm{G}$ (2001). Fitness, fatness, and coronary heart disease risk in adolescents: the Northern Ireland Young Hearts Project. Med Sci Sports Exerc 33:270-4.

- Calle EE, Thun MJ, Petrelli JM, Rodriguez C, Heath CW Jr (1999). Body-mass index and mortality in a prospective cohort of U.S. adults. $N$ Engl J Med. 341: 1097-1105

- Christou DD, Gentile CL, DeSouza CA, Seals DR, Gates PE (2005). Fatness is a better predictor of cardiovascular discase risk factor profile than aerobic fitness in healthy men.Circulation 111:1904-1914

- Dionne I, Almeras N, Bouchard C, Tremblay A (2000). The association between vigorous physical activities and fat deposition in male adolescents. Med Sci Sports Exerc 32:3925.

- Eckel RH (1997). Obesity and heart disease: a statement for healthcare professionals from the Nutrition Committee, American Heart Association. Circulation 96: 3248-3250

- Ekelund U, Poortvliet E, Nilsson A, Yngve A, Holmberg A, Sjostrom M (2001). Physical activity in relation to aerobic fitness and body fat in 14- to 15 -year-old boys and girls. Eur J Appl Physiol 85: 195-201

- International Society for the Advancement of Kinanthropometry (ISAK), 2001. International standards for anthropometric assessment. ISAK

- Janssen I, Katzmarzyk P.T, Ross R, Leon A.S, Skinner J.S, Rao D.C, Wilmore J.H, Rankinen T and Bouchard C (2004). Fitness alters the association of body mass index and waist circumference with total and abdominal fat. Obesity Research 12:525-537.

- Janz KF, Dawson JD, Mahoney LT (2002). Increases in physical fitness during childhood improve cardiovascular health during adolescence: the Muscatine Study. Int J Sports Med 23(suppl 1):S15-21.

- Jette M, Sidney K, Quenneville J and Landry F (1992). Relation between cardiorespiratory fitness and selected risk factors for coronary heart disease in a population of Canadian men and women. Canadian Medical Association Journal 146(3): 1353-1360.

- Klasson-Heggebø L, Andersen L.B, Wennlo"fA.H, Sardinha L.B, Harro M, Froberg K and $\Lambda$ nderssen S.A (2006). Graded associations between cardiorespiratory fitness, fatness, and blood pressure in children and adolescents. British Journal of Sports Medicine 40:25-29.
- Maffeis C, Corciulo N, Livieri C, Rabbone I, Trifiro G, Falorni A, Guerraggio L, Peverelli P, Cuccarolo G (2003). Waist circunference as a predictor of cardiovascular and metabolic risk factors in obese girls. Eur $J$ Clin Nutr 57 : 566-572.

- Mota J, Flores L, Flores L, Ribeiro JC, and Santos MP (2006). Relationship of single measures of cardiorespiratory fitness and obesity in young schoolchildren. American Journal of Human Biology 18:335-341

- Mota J, Guerra S, Leandro C, Pinto A, Ribeiro JC, Duarte JA (2002). Association of maturation, sex, and body fat in cardiorespiratory fitness. Am J Hum Biol 14:707-712

- Nassis G.P, Pasarra G and Sidossis L.S (2005). Central and total adiposity are lower in overweight and obese children with high cardiorespiratory fitness. European Journal of Clinical Nutrition 59:137-41.

- Ross R, Dagnone D, Jones PJ, Smith H, Paddags A, Hudson $R$, Janssen $I$ (2000): Reduction in obesity and related comorbid conditions after diet-induced weight loss or exercise-induced weight loss in men: a randomized, controlled trial. Ann Intern Med 133:92-103

- Ross R, Janssen I, Dawson J, Kungl AM, Kuk JL, Wong SL, Nguyen-Duy TB, Lee S, Kilpatrick K, Hudson R (2004): Exercise-induced reduction in obesity and insulin resistance in women: a randomized controlled trial. Obes Res 12:789798

- Sarria A, Moreno L.A, Garcia-Llop L.A, Fleta J, Morellon M.P and Bueno M (2001). Body mass index, triceps skinfold and waist circumference in screening for adiposity in male children and adolescents. Actar Paediatrics 90(4): 387-92.

- Stevens J, Cai J, Evenson K.R and Thomas R (2002). Fitness and fatness as predictors of mortality from all causes and from cardiovascular disease in men and women in the lipid research clinic study. American Journal of Epidemiology 156: $832-841$

- Thompson PD, Buchner D, Pina IL, Balady GJ, Williams MA, Marcus BH, Berra K, Blair SN, Costa F, Franklin B, Fletcher GF, Gordon NF, Pate RR, Rodriguez BL, Yancey AK, Wenger NK (2003). Exercise and physical activity in the prevention and treatment of atherosclerotic cardiovascular disease: a statement from the Council on Clinical Cardiology (Subcommittee on Exercise, Rehabilitation, and Prevention) and the Council on Nutrition, Physical Activity, and Metabolism (Subcommittee on Physical Activity). Circulation 107: 3109-3116

- Twisk J.W, Kemper H.C, van Mechelen W, Post G.B and van Lenthe F.J (1998). Body fatness: longitudinal relationship of body mass index and the sum of skinfolds with other risk factors for coronary heart disease. International Journal of Obesity and Related Metabolic Disorder 22(9): 915-22.

- Wilson PW, D'Agostino RB, Sullivan L, Parise H, Kannel WB (2002). Overweight and obesity as determinants of cardiovascular risk: the Framingham experience. Arch Intern Med.162: 1867-1872

- Yarnell J.W, Patterson C.C, Thomas H.F and Sweetnam P.M. Central obesity (2001): predictive value of skinfold moasurements for subscquent ischacmic heart disease at 14 years follow-up in the Caerphilly Study. International Journal of Obesity and Related Metabolic Disorder 25(10) $1546-9$ 